\title{
Diversity in the Maps of a Lisbon Neighbourhood: Community and 'Official' Discourses about the Renewed Mouraria
}

\author{
Leonor Bettencourt \\ Paula Castro \\ Instituto Universitário de Lisboa (ISCTE-IUL) \& CIS-IUL, Portugal
}

\begin{abstract}
The neighbourhood of Mouraria in the center of Lisbon is today home to three main groups of residents: traditional residents, new gentrifiers, and immigrants. This diversity is simultaneously a strength of and a threat to its social cohesion and its current urban rehabilitation process, undertaken by the City Council of Lisbon (CCL). This study has three main goals: 1) to analyze how the 'community identity' maps of the neighbourhood are constructed by residents' discourse; 2) to analyze how the 'official' cultural map of the neighbourhood is constructed in the discourses of the press and the CCL; and 3) to compare the 'official' and the 'community' maps. In drafting the 'community' maps, 22 interviews were conducted with traditional residents (14), new gentrifiers (6), and immigrants (2). The 'official' cultural map was re-constructed through a press analysis (four articles from two reference newspapers: Público, 2014; Expresso, 2013) and an in-depth interview with the coordinator of the CCL office in Mouraria. Findings show that the rehabilitation program is represented in the 'official' discourse in a more positive way than in residents' discourses. The main divergence concerns the targets of the intervention. However, in both discourses there is agreement regarding the social problems of Mouraria. The stories of the past told by traditional residents, although mentioning the loss of the traditional character of Mouraria, show the importance of public spaces for place attachment and place identity. The discourses of new residents highlight the role of places in building connections between past and present, and in helping maintain a sense of continuity. We discuss the importance of community identity mapping in understanding the 'battle of ideas' around urban rehabilitation and the impact that different perspectives can have. The study can be a source of information for decision-makers, helping strengthen the communication bridge between them and the community.
\end{abstract}

Keywords: community identity maps, official cultural map, place relations, multicultural community, rehabilitated neighbourhood

Résumé : Le quartier de Mouraria au cœur de Lisbonne est aujourd'hui habité par des habitants provenant de trois catégories sociales, soit: la population traditionnelle du quartier, les populations gentrifiées et les migrants. Cette diversité est à la fois une opportunité et un défi au

Leonor Bettencourt is a PhD student and a Research Assistant at CIS-IUL (Lisbon University InstituteISCTE-IUL) and works in Social and Environmental Psychology on subjects like urban context and intergroup relations. E-mail: leonor.bettencourt@iscte.pt. Paula Castro is professor of Social Psychology at the Lisbon University Institute-ISCTE-IUL, and a Researcher at CIS-IUL. Her research develops at the intersection of Social, Environmental, and Community Psychology and looks at the psychosocial processes involved in the acceptance of and resistance to social change, privileging a societal approach. E-mail: paula.castro@iscte.pt.

Culture and Local Governance / Culture et gouvernance locale, vol. 5, no. 1-2, 2015. ISSN 1911-7469

(C) Centre on Governance, University of Ottawa, 55 Laurier Avenue East, Ottawa, Ontario, Canada K1N 6N5 
processus de régénération urbaine développé par le Conseil de la ville de Lisbonne (CVL). Cette étude a trois objectifs: 1) comprendre l'identité communautaire et en faire une cartographie à partir des discours des différents résidents; 2) analyser comment la cartographie culturelle opérée par la presse et le CVL; 3) comparer les deux cartographies, soit la cartographie officielle et celle des résidents. Pour les fins de cette recherche, la cartographie des résidents a été produite à partir de 22 entrevues, dont 14 entrevues réalisées auprès de résidents dits traditionnels, six entrevues auprès des populations gentrifiées et deux entrevues ont été conduites auprès de migrants habitant le quartier. Pour sa part, la carte officielle a été réalisée par le biais d'une analyse presse (soit quatre articles provenant de Público, 2014; Expresso, 2013) et à partir d'une entrevue en profondeur réalisée auprès du coordonnateur du projet de revitalisation de Mouraria du CVL. Les résultats de cette enquête illustrent que la représentation officielle du projet est de loin plus positive que celle exprimée par les résidents. Les principales différences de perception se situent au niveau des objectifs du programme de revitalisation, bien que les deux discours reconnaissent les problèmes sociaux du quartier. Les discours des résidents traditionnels mettent en évidence un attachement mémoriel pour le passé, mais il illustre également l'importance de l'espace public dans les processus de construction identitaire. Pour sa part, le discours des nouveaux résidents met en relief l'importance du passé et du présent ainsi que la nécessité de préserver une certaine continuité dans cette ligne du temps $d u$ quartier. Cet article met en débat l'importance du conflit des représentations en contexte de régénération urbaine et les conclusions ouvrent sur des constats d'une grande utilité pour les praticiens du domaine.

Mots clé : carte d'identité de la collectivité, carte culturelle officielle, relations entre des endroits, communauté multiculturelle, voisinage restauré

\section{Introduction}

In recent decades, Lisbon's historic neighbourhoods have become increasingly depopulated and demographically aged (Malheiros, Carvalho \& Mendes 2012). However, a process of recentralization is now underway, reorganizing urban space and rehabilitating old places and sparsely inhabited areas (Rodrigues 2010). Current urban rehabilitation programs in central Lisbon, under the responsibility of the City Council of Lisbon (CCL), seek to renew the neighbourhoods through public works and through the involvement of residents, local actors, and stakeholders.

The younger middle class and younger immigrants have been attracted to some of these neighbourhoods, initiating processes of socio-ethnic transition and gentrification (Malheiros et al. 2012), developing new uses and generating new representations of the public spaces, as well as new forms of relating to the city (Menezes 2012). This means that the 'cultural maps' of the city and the neighbourhoods are being redesigned and different cultures redistributed. All of this makes this renewal not only a process of physical change, but also one of cultural change - a "battle of ideas" (Moscovici \& Markova 2000) expressing different voices and different representations of the space, its uses, and future projects.

One way of better understanding this type of complex cultural change is by exploring local perspectives about a place (Wharton \& Fenwick 2012), something that can be done by reconstructing the "cultural maps" (Crawhall 2008) with which different groups work. This means looking at memories, personal stories, and social representations of place, that is, looking at shared 
meaning systems (Castro 2012). Also crucial in this regard is an analysis of the correspondence between the 'cultural maps' of different resident groups ${ }^{1}$ and those of the authorities, which offer what can be called the 'official' discourse, the one often taken up by the press to be passed on in the public sphere.

The neighbourhood of Mouraria - a historic neighbourhood in central Lisbon, now home to traditional residents, new gentrifiers, and immigrants - appears as the perfect context in which to study these processes. First, it is currently undergoing a highly visible urban rehabilitation program developed by the CCL. Second, although it is a heterogeneous neighbourhood, there seems to be little interaction among the three groups of residents (Malheiros et al. 2012) and little is known about their relation to place and whether or not their 'cultural maps' of the neighbourhood diverge from one another.

In order to address these aspects of cultural change in Mouraria, this article first presents the neighbourhood. Second, it discusses the processes involved in mapping culture and relation to place. Finally, the study is presented: a comparison of the discourses of residents interviewed and the 'official' discourse re-constructed from press articles and based on an interview with a CCL expert.

\section{The neighbourhood}

Mouraria is an historical neighbourhood of Lisbon, climbing up a hill from the centre town towards the castle of São Jorge (Mendes 2012; Menezes 2012). The neighbourhood is one of the birthplaces of the traditional Portuguese music, Fado (Malheiros et al. 2012; Mendes 2012; Menezes 2012). It has an irregular urban plan, with multiple corners, alleys, and narrow streets (Mendes 2012). These features shaped the everyday life of the community by promoting tight social relations and giving Mouraria a unique character (Mendes 2012; Menezes 2012).

The neighbourhood dates its origins to 1170 , when the Moors and Jews of the city of Lisbon were forced to live in a gated commune around the castle (Menezes 2012). In the eighteenth and nineteenth centuries, the neighbourhood received people from other regions of the country and from Galiza, in Northern Spain. More recently, in the 1970s, Mouraria started to receive citizens from the Portuguese former colonies, and Asian immigrants (from India, Pakistan, Bangladesh, and China) began to arrive in the 1990s (Malheiros et al. 2012). Finally, between 2010 and 2014, Mouraria experienced two main processes of socio-urban transformation (Malheiros et al. 2012): some marginal gentrification and re-enforcement of the established Asian immigrant population. The first process - gentrification - refers to the influx of middle-class young adults with stronger cultural and academic capital than the traditional residents, although with weak economic capital and an unstable professional situation (Malheiros et al. 2012). These pioneers of the gentrification process prefer to live in central areas of the city due to their liberal and cosmopolitan lifestyle and the socially and ethnically tolerant environment that these offer (Rodrigues 2010). In Mouraria, most of them have a university degree and work in liberal professions related to cultural, artistic, or local social economy activities (Malheiros et al. 2012).

\footnotetext{
${ }^{1}$ For the sake of simplifying the text, whenever the word groups is used in this article, we are referring to 'groups of residents' in Mouraria.
} 
At this phase of the gentrification process, although rental costs are increasing, they are still affordable for the gentrifiers, and traditional residents can also still afford to remain in the neighbourhood. Therefore, changes to the physical space by these newcomers are minimal (Rodrigues 2010). However, an ongoing urban rehabilitation program started in the neighbourhood in 2010, aimed at solving multiple problems (e.g., unemployment, sense of insecurity, social exclusion of vulnerable groups), renewing it at the physical level (e.g., public squares and buildings) and motivating new people to visit and live in Mouraria (PDCM 2010). The local authorities involved in this rehabilitation project, newspaper articles, and tourism materials have recently produced what we will call here an 'official' discourse about the neighbourhood, in which it is described as a central piece of Lisbon's identity, and one of the places that contributes to making the city a top global tourist destination (Mendes 2012).

In sum, what we have today in Mouraria is small-scale gentrification centralized in specific places (Mendes 2012), residential ethnicization, and three groups of residents that seem to live apart, rarely interacting (Menezes 2012). Through these processes, the socio-cultural landscape of Mouraria has changed, and continues to change.

In this context, it is important to understand: 1) how the 'cultural maps' of the neighbourhood 'community identity' maps - are constructed by the discourses of different groups of residents; 2) the degree of difference or similarity between these 'cultural maps' and whether they present points of tension; 3) how the 'official' discourse (of CCL experts and of the press) constructs the 'cultural map' of the neighbourhood; and 4) if the 'cultural maps' of residents and the one proposed by the 'official' discourse are convergent or divergent.

We expect to find a diversity of 'cultural maps' within the neighbourhood, and also expect differences between these and the 'official' map. It is thus important to reflect on the potential impact that this diversity can have on the neighbourhood and its current rehabilitation program.

\section{Mapping the neighbourhood}

Different types of cartographic practices have been developed (e.g., cultural mapping, countermapping, community-based mapping, participatory mapping [Crawhall 2008]) in recent decades in order to pressure the 'official' institutions that define the 'official' maps to acknowledge local perspectives about a place. Cultural mapping is a process through which the cultural information of a community - such as material resources, networks, and patterns of place use - is collected, analyzed, and synthesized (Alzrooni 2011). As a tool for understanding the cultural context of a specific place, it prompts intercultural dialogue, helps communities manage their intangible heritage, and values diverse local voices (Crawhall 2008). It allows for a closer relationship between the community and those in a dominant position, or the hegemonic cultural interlocutors, such as the State (Crawhall 2008). In this sense, making the local authorities acknowledge the community's cultural values enables them to enrich public spaces and reflect local cultures in urban design planning (Duxbury 2014).

There are two main types of cultural mapping: one that identifies tangible cultural resources, and one that maps out the intangible cultural elements that define the collective identity and sense of place of a community (Alzrooni 2011). The latter is called community identity mapping, and is the type carried out in the present study for making the intangible elements of Mouraria visible. 
These elements show how residents relate to place and to their neighbourhood, and how the memory and heritage of a place relate to their identity.

\section{Different meanings, different cultural maps}

In order to understand the community identity maps of this diverse neighbourhood, it was important to explore how the different groups of residents represent the neighbourhood. In fact, different interpretations of the same place can emerge from different social groups and within the same group (Mellon 2008), reflecting the multiple identities that one can find in a particular neighbourhood. Therefore, we expected to find differing community identity maps among the different groups of residents in Mouraria, each one highlighting different intangible cultural resources that contribute the most to their relations with place.

The discursive constructions of a place are intertwined with material and social practices in space and are offered through discourse (Di Masso \& Dixon 2015; Dixon \& Durrheim 2000). The community identity maps of a neighbourhood are thus a result of how different groups relate to and give meaning to place, highlighting varying aspects of community heritage, memories, values, and uses of public space. As place becomes meaningful through memories and connections to the past, place attachment and place identity provide a sense of continuity over time (Sani et al. 2007; Droseltis \& Vignoles 2010; Smeekes \& Verkuyten 2014). This occurs especially in communities undergoing social changes as a result of the arrival of new elements from different cultures (Smeekes \& Verkuyten 2014), as in Mouraria, and becomes crucial to the development and maintenance of place identity.

Collective memories and long-term experiences promote the development of place identity and the appropriation and use of public spaces (Benages-Albert et al. 2015). Thus, the role of continuity (Sani et al. 2007; Droseltis \& Vignoles 2010; Smeekes \& Verkuyten 2014) is different for different groups. In our case, this means we could expect to find different uses of space and different 'cultural maps' among the different groups of residents, as well as different sources of a sense of continuity for traditional residents versus new ones.

For newcomers to a place, memories of previous places of residence play a crucial role in strengthening attachment to the current place of residence, linking different periods of life and giving continuity to past experiences of place (Rishbeth \& Powell 2012). Past memories can help people to envisage how everyday life continues in the new context and to develop feelings of rootedness (Ehrkamp 2005). These memories are expressed through material and social practices in the neighbourhood, especially by new immigrants (Ehrkamp 2005). By placing their identities in the public and private spaces of the neighbourhood they develop a new place-based identity (Ehrkamp 2005).

In rehabilitated environments, this is highly evident because the representations of place as 'new' and as 'reliving the past' clash with each other (Czaplicka \& Ruble 2003). As the sociocultural environment creates a sense of stability, it is important for people to be able to find identities in their community and to express those identities in the material culture (Mellon 2008). These different identities may present diverse community identity maps within the neighbourhood and be shared with or divergent from the 'official' map of Mouraria. 
It is also important to take into account that the cultural maps and discourses of residents as well as the 'official' discourse can have consequences for interventions in the neighbourhood. For instance, the discursive patterns expressed in the press about a neighbourhood neglected for many years can result in a 'naturalization' of the discursive order and the maintenance of a situation of social inequality (Mcguiness 2005). A focus on discourse is thus crucial for understanding how the social elements of a neighbourhood are shaped and naturalized in language, and the social order is maintained or challenged (Mcguiness 2005), as this can have an impact the development of the rehabilitation program.

\section{Specific goals}

In sum, identity mapping can be a useful tool for creating opportunities for dialogue between the community and the hegemonic cultural interlocutor (Crawhall 2008), as diverse sources of information can overcome the limitations of expert opinions. Hence, assessing the cultural maps of Mouraria is important for understanding the impact that different perspectives can have on the neighbourhood. To gain access to those perspectives, the study aimed to: 1) analyze how the various groups of residents of Mouraria construct the community identity maps of the neighbourhood through their discourses; 2) analyze how the 'official' cultural map of the neighbourhood is constructed; and 3) compare the community identity maps with the 'official' cultural map.

\section{Methodology}

To achieve the first goal, 22 interviews were conducted in the neighbourhood with 14 traditional residents, 6 new gentrifiers, and 2 immigrants. For the second goal, an analysis of two 'official' sources of information was undertaken: 1) a press analysis of four articles about Mouraria from two reference newspapers - Público (two articles in March 2014; one article in May 2014) and Expresso (one article in May 2013); and 2) an interview with the coordinator of the CCL office in Mouraria.

\section{Analysis and discussion - Community identity maps}

The 22 residents interviewed were asked to describe their neighbourhood, identify the 'subneighbourhoods' inside Mouraria, set its boundaries, identify which places they attend or use more, and point out the main transformations brought about by the rehabilitation program. The extracts that follow summarize and illustrate the main trends observed in residents' responses to two central questions: 1) How do you describe Mouraria and what are the major changes that you see in the neighbourhood due to its urban rehabilitation?; and 2) Can you identify different neighbourhoods inside Mouraria? We will start by analyzing the responses of the different groups to the first question, starting with the group of traditional residents, followed by new gentrifiers, both groups together, and, finally, immigrants.

\section{Traditional residents}

The 14 traditional residents interviewed describe the social environment of the neighbourhood as having become less familiar. Although the feeling of living in a traditional community still exists, it now coexists with descriptions of a changing place, in which relations are less close and less 
familiar. The interviews suggest that a sense of the typical and traditional neighbourhood remains among these residents (for instance, Fado and Marchas Populares are traditional activities mentioned) and is part of their identity, despite the socio-cultural transformations that have occurred with the arrival of new residents. Hence, we can suggest that continuity is described as threatened, although still present:

People no longer interact as much as back in the old days, but when we need something, if we scream out, people came quickly asking "what's going on?" ... Nowadays it [Mouraria] is different, because many people live here that don't feel what we feel, but the Portuguese people feel the neighbourhood truly. (TR2) ${ }^{2}$

... back in old days everyone knew each other, this was almost like a family. Even nowadays I walk in the neighbourhood and elderly people say "hi miss M., how are you?" It was almost like a family, but unfortunately that is also ending. (TR3)

Moreover, although Fado continues to be one of the central symbols of the cultural environment of Mouraria, some state that it has now been appropriated by people who do not belong to the neighbourhood, which threatens its authenticity and sense of continuity:

... the Casa de Fados was constructed, there in the Casa de Maria de Severa, but it is a person who does not belong to the neighbourhood that is in charge of it ... he is an expert in Fado ... But, he is a person from outside the neighbourhood.... I am sorry that the people from the neighbourhood were not considered. (TR6)

Regarding the uses of space, traditional residents point out that today there are fewer resources in the neighbourhood. Back in the old days, they had most of the products and services they needed, but now, since commerce has changed a lot and the old cafés they used to go to have closed, the conviviality in the neighbourhood has also been transformed, and people no longer know each other so well:

What I liked the most was what we had in early days. We didn't need to go to the supermarket. We had everything. There was everything here. (TR3)

They also pointed out that the population of the neighbourhood is elderly, few children live there, and there is a high percentage of immigrants. These are seen as residents that do not settle in the neighbourhood, and yet have a strong influence there due to their large involvement in business:

All the immigrants that I know are here just to get the documents to get out of here, or to go to another country. (TR6)

\footnotetext{
${ }^{2}$ All interview and press translations by the authors.
} 
In sum, although a feeling of living in a traditional neighbourhood still exists, it comes together with the feeling that a sense of community and continuity is being lost. Traditional residents mention that this loss has brought a less familiar environment and less close relations. Additionally, some mention that the traditional character of the neighbourhood has been appropriated by people who do not belong to Mouraria, as in the case of the recovering of traditions such as Fado, and the increasing number of immigrants living or working in the neighbourhood. Therefore, the discourses of traditional residents express a desire to go back to a past time, when Mouraria was more traditional, and feelings of community and continuity were stronger. Thus, there are indications of a nostalgic discourse about a changing place.

\section{New gentrifiers}

The six new gentrifiers interviewed describe Mouraria as being simultaneously a multicultural and a traditional neighbourhood where they can find a sense of community. They recount how they have chosen to live in Mouraria due to the closeness of the neighbours' relationships. Their narratives also highlight the role place plays in forming connections between prior places of residence and current ones, and helps maintain a sense of continuity in identity development. They mention how the environment of the current neighbourhood reminds them of previous contexts in which they lived (e.g., neighbourhoods in Barcelona, London, and Lisbon). The interviews suggest that a sense of place can result from the sense of continuity through different places and periods.

It's a real neighbourhood and that's something you can feel in how people interact with each other, people greet me, people know who you are, greet you when you go to a bar or a supermarket. The neighbours too. There's a real good relationship, they are always ready to help you. And that was a thing that I was partly missing and which now I found. (NG1)

When I was a child I used to play on the street, we played in the street until late, said "hello" to people, people recognized us and where I live now is the same thing. You see the kids walking in the street, running, playing football, riding bicycles. And yes, for that aspect it reminds me of my childhood. (NG1)

So, the only places where I found children playing on the street, from all those places I've passed, was in Ajuda, where I played in the street .... (NG2)

In sum, the sense of community that traditional residents describe as being lost is mentioned by new gentrifiers as one of the main characteristics of Mouraria. This neighbourhood is the place where they have found the same feeling of a close community that they had in previous places of residence: thus, they found continuity here.

\section{Traditional residents and new gentrifiers}

Both traditional residents and new gentrifiers identify the increasing number of houses sold to tourists as one of the main factors of transformation of the neighbourhood. Some mentioned that the 
interventions made through the rehabilitation program were mostly directed to people from outside Mouraria and that the residents were not sufficiently involved in the decisions, a fact that is endangering the memory of the neighbourhood's culture. Additionally, although there has been a tremendous number of new socio-cultural projects and activities developed in the neighbourhood, some mention that many of these are seen as failing to fulfill the needs of the residents:

I really don't know if the projects are directed to them too, I don't know. ... There are many associations now. For me the challenge is how to attract people in real need. These ones are not always involved and there will always be a number of people against the projects. (NG3)

Another issue is the accelerated transformation of the commercial landscape. If once it was more traditional and diversified, today it is constituted almost exclusively by immigrants' stores (e.g., Chinese, Bangladesh, and Indian):

[describing the commerce in her area of residence] ... Bangladeshi, there are three, four, five stores everywhere. Regarding resources, we also have the Chinese people over there. ... Now we have here Punjabi, Bangladesh, Punjabi, Nepal, Punjabi, Bangladesh, Bangladesh, yes. They no longer exist here [referring to Portuguese stores]. (TR6)

\section{Immigrants}

The two immigrants interviewed were living in Mouraria for one and two years respectively and they recognized that one of the reasons that made them move to the neighbourhood was the fact that there were Chinese people already living there. They describe their main daily activities as occurring mostly outside the neighbourhood and with people from the same culture of origin. Their use of the neighbourhood is almost exclusively related to their jobs, as both work in the neighbourhood:

We work long hours, we start here at 10 a.m. and this closes at 11 p.m. We only have one day off per week. So, we don't have much time to go for walks. ... And on my day off I go out more to other areas. I go to Colombo, the shopping center, and the Vasco da Gama [shopping] centre. (I2)

The presence of Chinese in the workplace and the neighbourhood may allow them to link their current place of residence with their culture of origin and to develop feelings of rootedness in this place. Therefore, it may suggest the same continuity expressed in new gentrifiers' discourses. However, we have to take into account that we have only two interviews with immigrants, so further work is needed to substantiate this finding. 


\section{Convergence and divergence in resident discourses}

The various interviews offered different community identity maps, which expressed different representations of Mouraria. Traditional residents' stories express a feeling of loss of a sense of community due to the changes that have occurred, and the appropriation of commerce by people who do not belong to the neighbourhood. However, if the traditional residents feel a growing threat to the identity of Mouraria as it is now, at the same time they also feel a sense of continuity.

Contrary to this more regressive discourse, the discourses of new gentrifiers represent Mouraria as a place that offers precisely that community feeling and prompts the growth of connections to prior places of residence. This continuity between different places of residence is also found in the discourses of immigrants. Both look for common experiences between the present neighbourhood and past residences. Yet very little is known at this point about how immigrants relate to the neighbourhood.

This diversity of community identity maps found within the neighbourhood allowed us to identify possible tensions between the different groups of residents and a lack of intergroup interaction in the neighbourhood. The interviews reveal mostly intragroup interaction. Traditional residents, in particular, talk about the feeling of mutual assistance between neighbours that persists in the neighbourhood, and about Marchas Populares as one of the main moments when they interact with each other.

Although new gentrifiers like the neighbourhood, and connect it to prior places of residence where a feeling of neighbourliness was present, their daily life activities are only marginally carried out in Mouraria. We can say that they appreciate the image of a traditional neighbourhood, but do not fully participate in its everyday life.

The immigrants also seem to carry out most of their daily activities in other places of Lisbon. Their interaction with other groups of residents happens only in the context of their work activities, specifically, in stores and restaurants. This much is stated by both the immigrants interviewed and by the interviews of the other residents. However, we have only two interviews with immigrants, so further work is needed to fully substantiate this finding.

In sum, the discourse of residents reveals that there is very little intergroup interaction, corroborating what was previously suggested by Malheiros et al. (2012). On the part of traditional residents, there are potential tensions with the other groups because some fear that they may alter the traditional character of the neighbourhood.

We will now analyze how residents divide the neighbourhood into different areas (question 2). The interviewees identify different areas in the neighbourhood according to specific groups of residents and the type of commerce. The neighbourhood can be divided into two major areas: one with a strong multicultural character and the other with a more traditional feel:

Inside Mouraria there are two neighbourhoods. There is the traditional Mouraria, and then the other Mouraria that is completely multicultural. ... It's more the habits, more the routines from this side and the other [that delineates the boundaries between the two neighbourhoods]. (TR1) 
Place relations can be a means for residents to map the neighbourhood socially and culturally, creating an emerging image of different areas of the neighbourhood associated with various groups of residents. Therefore, besides those two main divisions, the interviewees also describe six 'subneighbourhoods' inside Mouraria (see Figures 1 to 7).

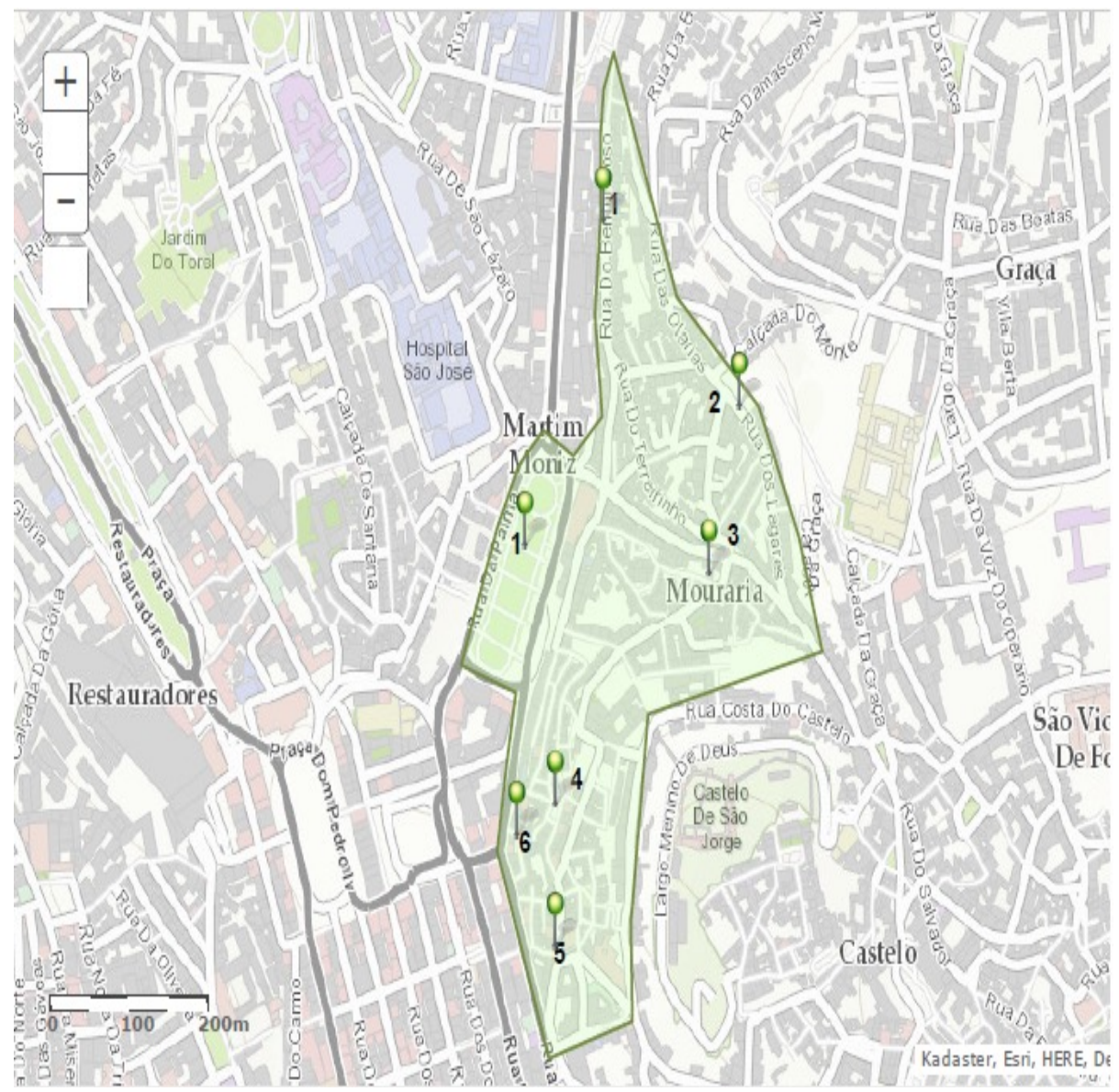

Figure 1. Map of Mouraria with the six 'sub-neighbourhoods' identified by the residents: 1) Martim Moniz and Rua do Benformoso; 2) Olarias and Largo do Terreirinho; 3) Rua do Capelão, Rua da Guia, and Rua da Amendoeira; 4) Largo dos Trigueiros; 5) São Cristóvão; and 6) Beco do Rosendo. Source: ArcGIS 


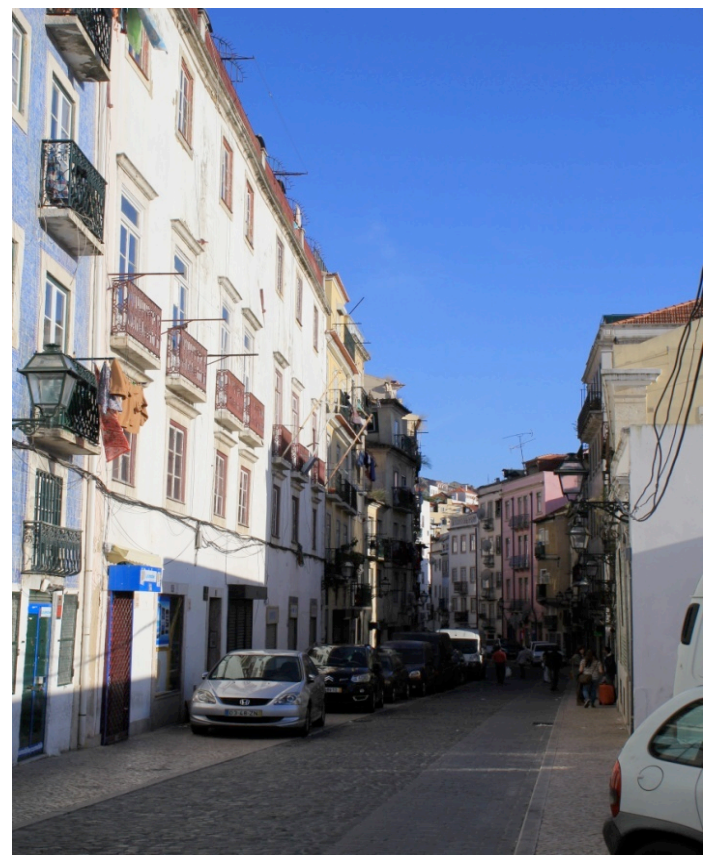

Figure 2. Rua do Benformoso: Sub-neighbourhood 1 - High concentration of immigrants and their commerce. Source: Authors

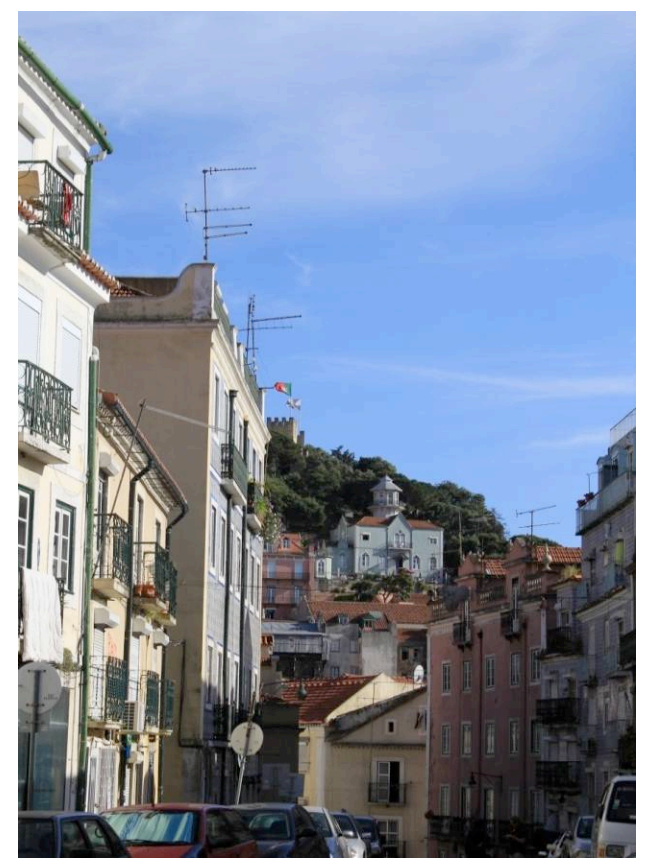

Figure 3. Largo das Olarias: Subneighbourhood 2 - High concentration of traditional residents. Source: Authors

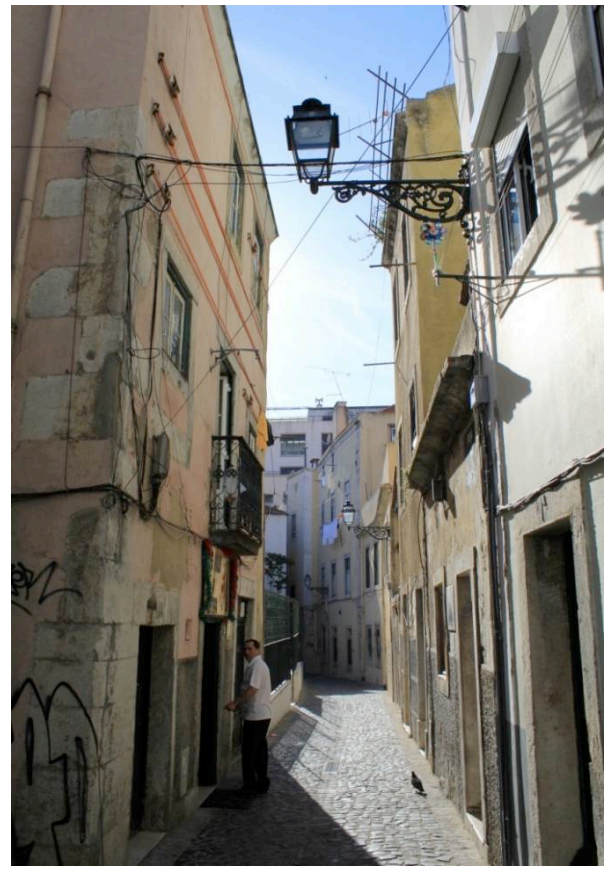

Figure 4. Rua do Capelão: Subneighbourhood 3 - The typical or the 'real' Mouraria for some (interviewee TR1). Source: Authors

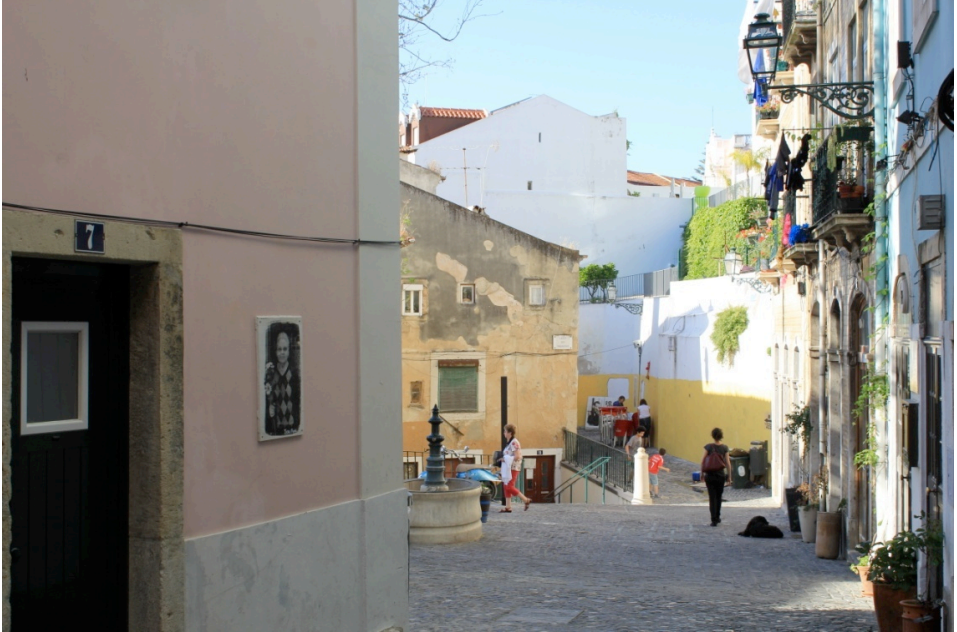

Figure 5. Largo dos Trigueiros: Sub-neighbourhood 4 - With a concentration of new gentrifiers and some traditional residents. Source: Authors 

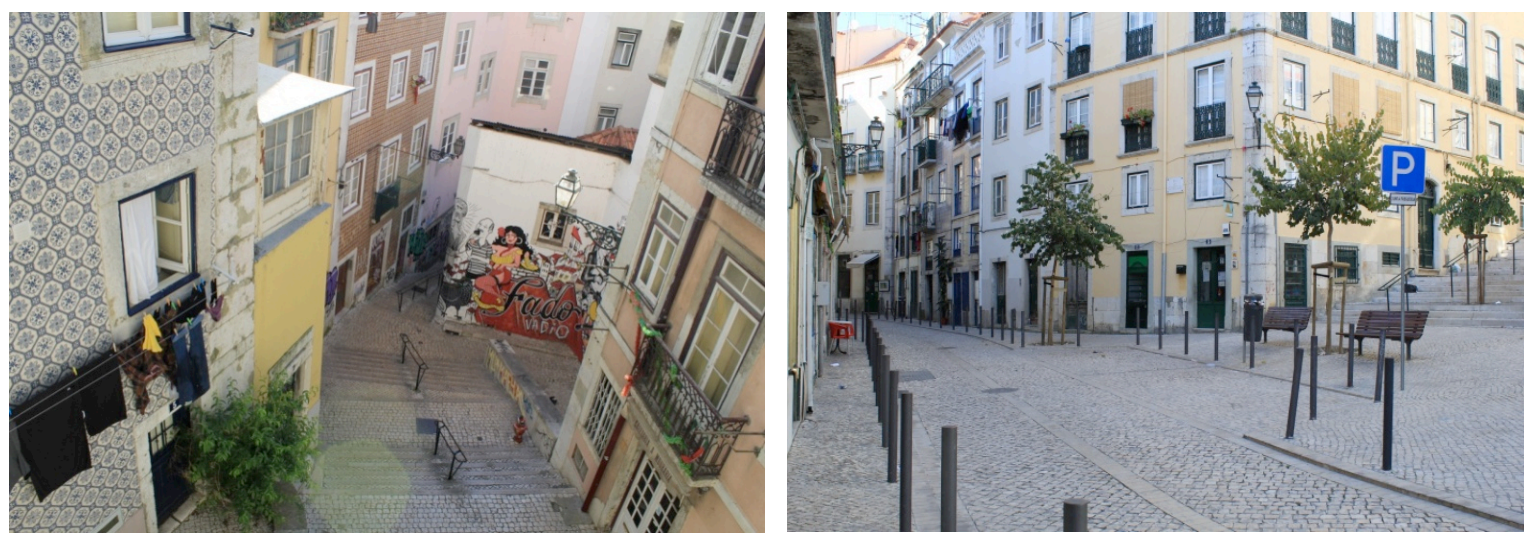

Figure 6. São Cristóvão: Sub-neighbourhood 5 - Described as the 'new' Mouraria (interviewee TR6). Source: Authors

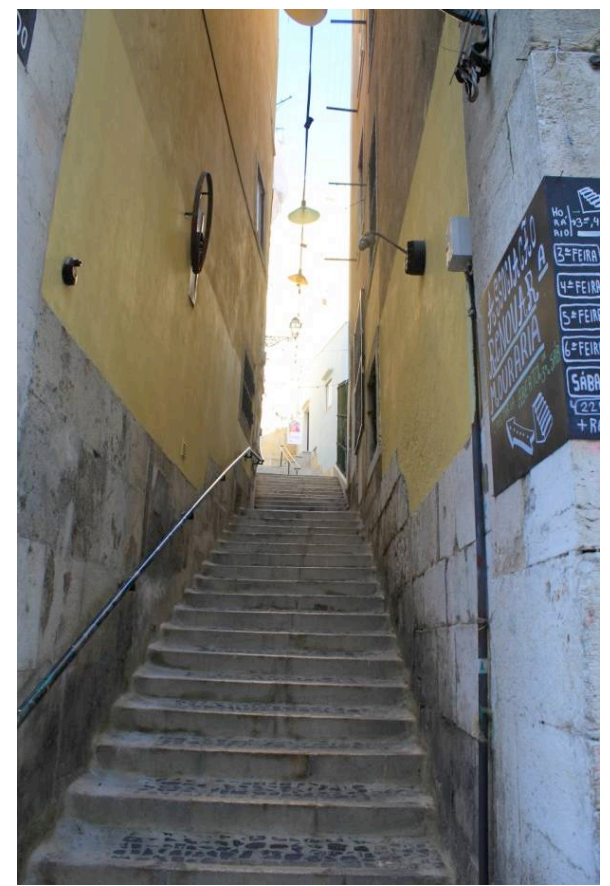

Figure 7. Beco do Rosendo: Sub-neighbourhood 6 - Considered one of the boundaries of Mouraria. Source: Authors

\section{Analysis and discussion - 'Official' discourse}

We now turn to analysis of the cultural maps that the 'official' discourse about the neighbourhood offers, that is, the discourse of the local authorities and taken from the press. Overall, the neighbourhood is represented as one of the most attractive places in Lisbon to visit and live in. The transformations made by the CCL program are presented as successful for the residents and for tourism. Even though Mouraria is described as a multicultural community, its cultural diversity is not presented as a threat to its social cohesion, but instead as a strength, and the neighbourhood is represented in the 'official' discourse as a place where different groups of residents interact. In this 
section, we first analyze the press content and then the interview with the City Council Coordinator so as to address specific issues explored by both sources. ${ }^{3}$

\section{Press analysis}

The newspaper articles analyzed represent the neighbourhood as part of a new trend in Lisbon. It emphasizes the transformation of the neighbourhood from a ghetto into a successfully renewed place where an increasingly large number of people want to live. The places pointed out as representing the most substantial changes brought about by the rehabilitation actions were Martim Moniz and Intendente. Mouraria is described as a place on the tourist itinerary of Lisbon - a promising place to invest and start a new business:

Mouraria entered not only the touristic itinerary of Lisbon, but became also one of the most wanted neighbourhoods of the capital for investors and young adults that want to live there. (Expresso, 2013)

In the press, traditional residents are described as being initially suspicious of what the rehabilitation program would bring to the neighbourhood, but after the renovation of some buildings, they are presented as recognizing that the physical environment of the neighbourhood was renewed.

The neighbourhood is defined in the press not only by its multicultural character, but also by its familiar and traditional environment and neighbourliness. On the other hand, the press also reports the main social problems of Mouraria identified by the CCL, such as prostitution, unemployment, and drug trafficking and addiction. These last two problems are described in the press as an issue that residents do not speak of freely, almost as if it was a secret:

"Now only rarely do we see them [drug dealers] climbing the streets, but the trafficking activity nevertheless remains strong," say the residents, as if they were confessing a secret. (Expresso, 2013)

The press divides Mouraria into three 'sub-neighbourhoods': 1) São Cristóvão, the more wealthy area; 2) Rua do Capelão, where the old residents live; and 3) between Olarias and Intendente, represented as a marginalized area.

The rehabilitation program of the CCL was expected to end in 2014. The discourse in the press (Público, 2014) describes it as successful in achieving the main goals of the intervention. In fact, the CCL office placed in Intendente will close in order to reopen and start a new intervention in another area of Lisbon:

The mayor will leave the office located in Intendente for [the last] three years and will go back to Paços do Concelho, at least during his "search for other Mourarias." A.C. congratulates himself on the progress achieved in this area, namely employment

\footnotetext{
${ }^{3}$ All press articles translated by authors.
} 
creation ... this methodology [of the rehabilitation program] can now be replicated "in other areas of the city": "There are other Mourarias in town where we have to intervene." (Público, 2014)

However, it is also assumed that some problems still remain in the neighbourhood, and need to be solved:

"It was very important what was done, but also what is still planned to do," said the mayor, recognizing that there are "structural problems" to solve and public works to do. (Público, 2014)

"Unfortunately, we are victims of our own success.... This is provoking market inflation. This means higher prices, making it more difficult for new families to settle." (Público, 2014)

In sum, the neighbourhood is described in the press as one of the most attractive places in Lisbon today, both for tourists and new residents. Its discourse has, in general, a positive connotation when Mouraria is presented. There is also a tendency to present the rehabilitation program as successful.

\section{Interview with the Coordinator of the City Council of Lisbon Office}

The coordinator of the CCL office placed in Mouraria describes the neighbourhood as a multicultural place, where different cultures live side by side and the traditional residents now have a positive attitude towards the neighbourhood. He emphasizes the success of the rehabilitation program in improving the quality of life of residents and in bringing in new residents. He mentions how the mixture of old and new residents transformed the neighbourhood into a multicultural and diversified place. According to him, people are living peacefully with these changes, and the new cultures brought by the new residents are not a threat to the traditional character of Mouraria:

Mouraria is the most multicultural area of the country, where there is the highest concentration of immigrants with different backgrounds.

[the intervention was made] without forgetting the background, ... and without preventing people from walking freely in the neighbourhood. Today there are more diversified people here ... and that was a goal [of the intervention]. I think that it [the social relationship] has been going well between the new and the old residents that live here. ... We didn't want the old or the traditional to be replaced by a new community or a new exogenous youth. We want this to become a learning opportunity for those who were already here.

In general, the neighbourhood is presented as a place that has continued to evolve since rehabilitation began, and has become increasingly less stigmatized: 
Today people are much more positive, cosmopolitan and open.

The most important social problems highlighted, which the program was and is directed to solve, are drug addiction and trafficking, prostitution, unemployment, and lack of safety. Although these problems have not been extinguished, the CCL and the local associations are seen as doing an important and evolving job in solving them:

The social problems that existed here ... we saw some people on drugs, assaulting others.... Today we have here former prostitutes, women from 20 to 50 years old, who are now enrolled in educational courses [in Mouraria], people addicted to drugs are being helped by specialized offices [located in Mouraria] ... we gained a positive reputation among these groups and gradually we are calling upon them to change.

When describing the development of the intervention made in the neighbourhood, the CCL Coordinator points out that the initiatives to change the stigmatized image of Mouraria began with certain resident associations. When, in 2010, the CCL announced the urgency of renewing the neighbourhood, the Community Development Plan of Mouraria began. According to him, this plan was made in collaboration with the residents and local associations that were already trying to make a difference:

The CCL applied [for community funding] in partnership with a group of local institutions... The aim of the application was mainly the physical dimension of urban rehabilitation.

However, he also points out that this cooperation with residents was not a priority in the initial phase of the application for community funding; he states that only later, when the CCL realized the urgency of intervention at the social level, was the community of Mouraria consulted:

We never had a close relationship with people ... during the QREN phase [initial funding phase]; there was no participatory planning. We never had meetings with them..., no one asked them what they wanted to change for the better. When we started to intervene at the social level, we felt a strong resistance, and distrust from people.

Another issue taken into account by the CCL when applying for community funding was the boundaries of the urban area to be rehabilitated. The coordinator explains that São Cristóvão and Intendente were included in the project precisely because of funding issues, extending the boundaries of what is considered Mouraria by the residents:

We extended the urban area of Mouraria for funding application reasons, so we could also include public works in São Cristóvão and Intendente. 


\section{Comparing the discourses of residents with the 'official' discourse}

In order to subsequently compare the discourses of residents and the 'official' discourse, identifying their convergences and divergences, we start by presenting a summary of their contents (Table 1). This summary systematizes what was presented in the previous sections and is organized along the three major themes or dimensions of analysis that emerged from the interviews, and from which different cultural maps (Crawhall 2008) can be reconstructed. The three dimensions are the following: 1) social environment - how the social and cultural environment of the neighbourhood is presented; 2) social problems - how the main social problems of the neighbourhood are described; and 3) rehabilitation program - the principal transformations that are seen in the neighbourhood due to the rehabilitation program and how the intervention is described.

The summary in Table 1 shows how, regarding the social environment, the traditional residents interviewed expressed concern over a growing threat to the identity of Mouraria due to the arrival of new residents and the appropriation of some traditions by people who do not belong to Mouraria, yet at the same time they still feel a sense of continuity. In contrast, new gentrifiers describe Mouraria as a place that offers precisely the community feeling they desire and seek out in a place of residence and a feeling that reactivates memories of prior places of residence, re-connecting them to those places. This continuity is also found in the discourses of immigrants. A characteristic found in all discourses is the fact that Mouraria is described as a simultaneously multicultural and traditional neighbourhood. The 'official' description of the neighbourhood focuses more on the advantages of the new sociocultural environment, and on the end of the stigmatization associated with the old Mouraria. In addition, traditional residents, new gentrifiers, and the press view the exponential growth of tourism as a major recent characteristic of Mouraria, which makes the neighbourhood a new pole of attraction.

In regards to the second dimension, the main social problems identified by traditional residents and new gentrifiers concern the persistence in the neighbourhood of drug trafficking and addiction and unemployment. The CCL Coordinator and the press also identify these problems, as well as prostitution and a lack of safety.

In regards to the rehabilitation program, residents admit that there were beneficial changes in Mouraria due to the program. However, they also mention that certain sociocultural projects did not fulfill or meet their real needs. The 'official' voices present the program as being very successful, and underline the involvement of residents and local actors in the intervention actions. These voices also admit that the main social problems, such as unemployment and drugs, persist. However, the press presents the program in an even more positive light than the CCL Coordinator: although he highlights the beneficial outcomes of the program, he simultaneously recognizes that residents were not completely involved in the decisions from the beginning. 
Table 1. Three dimensions organizing the discourses of Mouraria of residents, the press and the CCL coordinator

COMMUNITY DISCOURSES

Residents
'OFFICIAL' DISCOURSE

Press

City Council Coordinator

\section{SOCIAL ENVIRONMENT}

\section{Traditional Residents}

Environment now less traditional, but a sense of community still exists.

Population elderly, low percentage of children, high percentage of immigrants.

New Gentrifiers

Place both traditional and multicultural.

Sense of community and closeness in neighbours' relationships.

Traditional Residents and New Gentrifiers Increasingly high number of houses sold to tourists as one of the main factors of cultural transformation.

Immigrants

Culturally diverse neighbourhood.
Neighbourhood described as part of a new trend in Lisbon.

Transformation from a ghetto to a renewed neighbourhood, where an increasing number of people want to live.

Now placed on the tourist itinerary of Lisbon.

Simultaneously multicultural and traditional.
More cosmopolitan neighbourhood.

Transformation from a ghetto to a renewed neighbourhood, where an increasing number of people want to live.

Simultaneously multicultural and traditional.

\section{SOCIAL PROBLEMS}

Traditional Residents and New Gentrifiers Drug traffic and addiction and unemployment still persist in the neighbourhood, but are seldom mentioned.
Residents afraid of talking freely about drug addiction and traffic.

Drug traffic and addiction, prostitution and unemployment identified by the CCL.
Drug traffic and addiction, prostitution, unemployment, lack of safety.

\section{REHABILITATION PROGRAM}

\section{Traditional Residents}

Memory of neighbourhood traditions: Fado continues to be a major cultural symbol, but has been appropriated by people from outside.

Traditional Residents and New Gentrifiers Too directed to people outside Mouraria.

Many of the multiple new socio-cultural projects and activities seen as failing to fulfill the residents' needs.

Transformation of commerce from more traditional and diversified to almost solely constituted by immigrants' stores (e.g., Chinese, Bangladesh, Indian).

Residents not sufficiently involved in decisions.

\section{Immigrants}

Some buildings rehabilitated but no mention of social changes.
Martim Moniz and Intendente described as the main places that changed the most.

Old residents recognized that part of the physical environment of the neighbourhood was renewed.

Neighbourhood as a promising place to invest and start a new business.

Program successful.
Martim Moniz and Intendente described as the places that changed the most.

Objectives of the program: improve the quality of life of residents and workers and attract new residents

Recognition that some problems remain in the neighbourhood.

Intervention made together with residents and local associations. BUT

Recognition that residents were not directly consulted at the beginning of the intervention.

Program successful. 
Both community and 'official' discourses converge in some of the themes summarized. The major convergence relies on the image of a neighbourhood with a strong sense of community and a traditional way of life. This suggests that the community identity maps of the new residents are more attuned to the 'official' cultural maps than are the community identity maps of traditional residents. Both the traditional residents and the coordinator point out the importance of the preservation of the traditional character of Mouraria. Even so, they do not agree entirely on how the combination of the 'new' and 'old' Mouraria is being conducted. It seems that both are concerned with ensuring the cultural continuity of the neighbourhood. Also convergent between both discourses are the social problems of the neighbourhood identified by traditional residents, new gentrifiers, the CCL Coordinator, and the press - drug trafficking and addiction and unemployment.

The biggest divergences between the community discourse and the 'official' discourse concern the transformations and interventions of the rehabilitation program. Residents say that the rehabilitation program failed to fulfill residents' needs because it was aimed at tourism and has promoted the growth of a non-traditional commerce. For the CCL Coordinator, the intervention conducted in Mouraria was successful and was made together with residents and local associations, although he admits that this local cooperation was not solicited at the beginning of the program. Although residents and the CCL Coordinator disagree on the development of the program, they both express the representation that Mouraria has become more cosmopolitan and a place on the tourist itinerary of Lisbon.

The main difference between the community identity map and the 'official' map lies in how to preserve the cultural continuity of the neighbourhood. In this sense, allowing the local authorities to access the cultural maps of the residents can be an advantage for the success of the rehabilitation program. They can make decisions regarding urban interventions in a more effective way by better responding to residents' needs. This shows the importance of mapping in enabling a genuine dialogue between the community and a hegemonic interlocutor, in this case, the CCL Coordinator.

A further aspect of discourse by the residents, the press, and the CCL Coordination concerns the way different areas of the neighbourhood are represented. The resident interviews suggested that feelings of attachment to particular places in the neighbourhood define the distribution of groups of residents inside the neighbourhood, identifying also how these groups use public space. Based on this distribution, residents divide Mouraria into six major areas corresponding to six different 'subneighbourhoods'. Such a division of residents is somewhat divergent from the division scheme presented in the press and by the CCL Coordinator. The main difference concerns the geographical area of the city that is considered Mouraria. The rehabilitation program defines Mouraria in a more inclusive way by including São Cristóvão and Intendente. The former is considered to be the new Mouraria by the traditional residents and new gentrifiers, due in part to this characterization in the 'official' map. However, Intendente is not viewed by any of the residents interviewed as being part of Mouraria.

In sum, the community identity maps offer a representation of Mouraria based on three main issues: 1) there are increasing numbers of houses being sold to tourists; 2) the major social problems of the neighbourhood are related to drugs and unemployment; and 3) the rehabilitation program was strongly oriented towards attracting people from outside Mouraria and for tourism purposes. However, there are points of divergence. Whereas the traditional residents describe a progressive 
loss of a sense of community and cohesion, the new gentrifiers describe the neighbourhood as offering community and cohesion.

The description of a neighbourhood with a strong sense of community is also conveyed by the 'official' discourse. The community and 'official' discourses also converge with regard to the social problems of the neighbourhood.

The major divergence between both discourses concerns the transformations and interventions of the rehabilitation program. The press and the CCL Coordinator represent the rehabilitation program in a more positive way than does the community discourse. Both residents and the CCL Coordinator want to preserve the cultural continuity of Mouraria, but they disagree on how the intervention should be made.

\section{Conclusion}

The cultural maps of the residents, the press, and the CCL Coordinator have shown how the "battle of ideas" (Moscovici \& Markova 2000) among different shared meaning systems (Castro 2012) are battling in the public sphere and have been 'guiding' some urban policies in the neighbourhood. The interviews conducted for this study offered different community identity maps, expressing different representations of Mouraria, and diverging in various dimensions from the 'official' map.

We wanted to explore how the transformations of a neighbourhood undergoing a process of rehabilitation are expressed in how people represent and map it. We also intended to show how the same place can be an object of different discourses, according to people's relations to place. This study suggests that, in rehabilitated neighbourhoods, it is important to systematically analyze the relationships between the 'official' cultural maps and 'community identity' maps in order to follow how the intervention develops and to understand its weaknesses and strengths.

The community identity maps also revealed little intergroup interaction in Mouraria, as suggested previously by Malheiros et al. (2012). The daily life activities of new residents are carried out mostly outside the neighbourhood and thus do not provide the opportunity for groups of residents to interact with each other. However, the lack of intergroup interaction may also result from other psychosocial processes related to place attachment and to people's psychological representations of space. We can also hypothesize that the lack of intergroup contact could have been minimized if the local authorities had been aware of the community identity maps during earlier stages of the intervention. Knowledge of community perspectives about Mouraria could have assisted the CCL in taking actions to enrich public spaces in order to promote social cohesion and more intergroup contact among residents.

Another hypothesis we can raise is that by constructing an overly positive image of the neighbourhood, the press and the CCL risk creating an intervention less targeted to the real needs of the residents, and directed more towards the people who visit the neighbourhood. This does not mean that the rehabilitation program did not succeed in general. We only suggest that this representation of a flawless intervention may neglect some dimensions of the social and relational environment of the neighbourhood.

The present study illuminates the consequences that processes of urban rehabilitation may have for place relations in a culturally diverse community - especially for a place characterized by a strong place identity based on stories and memories that are still very important to and lived by 
traditional residents. Mouraria is a place that epitomizes what it means to be a citizen of the historical neighbourhoods of Lisbon (Mendes 2012; Malheiros et al. 2012). A threat to this identity may push older residents to abandon the neighbourhood, leading to growing gentrification and ethnicization instead of to a more integrated place. This makes us rethink what it means 'to be Mouraria'. We may recognize that the neighbourhood is now a different place and that there has been a break from its past. There are now two main images about the neighbourhood, present in the diversity of the cultural maps identified, that may be battling for dominance: the first is the image of a traditional neighbourhood; the second, an image of a more cosmopolitan place. The development of the second would mean continuing to sell houses to tourists and representing Mouraria as a 'brand' of Lisbon. Achieving a neighbourhood able to accommodate both images requires rethinking how to integrate the traditional identity and memories of older residents with the challenges presented by the physical and social transformations of today.

In sum, by illuminating the diversity of the cultural maps about a neighbourhood undergoing a rehabilitation program, this study can be a source of information for urban rehabilitation policies and decision-makers, helping to create communication bridges among multiple voices (Crawhall 2008). This can also help overcome the limitations of expert models that do not always recognize the need for a bottom-up approach in urban intervention, bridging the gap between official institutions and the community.

\section{References}

Alzrooni, S.A. (2011, August). Using participatory mapping methods to visualize the cultural resources: a case study of Dalton, GA. Project presented at the Dalton Mayor and Council Meeting, Dalton.

Benages-Albert, M., Di Masso, A., Porcel, S., Pol, E. \& Vall-Casas, P. (2015). Revisiting the appropriation of space in metropolitan river corridors. Journal of Environmental Psychology, 42: 1-15.

Boaventura, I. (2014, March 26). António Costa regressa aos Paços do Concelho "à procura de novas Mourarias." Público.

Castro, P. (2012). Legal innovation for social change: Exploring change and resistance to different types of sustainability laws. Political Psychology, 33: 105-121.

Crawhall, N. (2008). The role of participatory cultural mapping in promoting intercultural dialogue. Report prepared for UNESCO.

Czaplicka, J.J. \& Ruble, B.A. (2003). Composing Urban History and the Constitution of Civic Identities. Baltimore \& London: Johns Hopkins University Press.

Di Masso, A. \& Dixon, J. (2015). More than words: Place, discourse and the struggle over public space in Barcelona. Qualitative Research in Psychology, 12: 45-60.

Dixon, J. \& Durrheim, K. (2000). Displacing place-identity: A discursive approach to locating self and other. British Journal of Social Psychology, 39: 27-44.

Droseltis, O. \& Vignoles, V.L. (2010). Towards an integrative model of place identification: Dimensionality and predictors of intrapersonal-level place preferences. Journal of Environmental Psychology, 30: 2334.

Duxbury, N. (2014). Cultural governance in sustainable cities. Kult-ur: Interdisciplinary Journal on the Culture of the City, 1(1): 165-182. 
Ehrkamp, P. (2005). Placing identities: Transnational practices and local attachments of Turkish immigrants in Germany. Journal of Ethnic and Migration Studies, 31(2): 345-364.

Guerreiro, A. (2014, March 14). My Neighbourhood instalou-se na Mouraria para "reanimar" a vida do bairro. Público.

Malheiros, J., Carvalho, R. \& Mendes, L. (2012). Etnicização residencial e nobilitação urbana marginal: processo de ajustamento ou prática emancipatória num bairro do centro histórico de Lisboa? Sociologia, Revista da Faculdade de Letras da Universidade do Porto, Número Temático: 97-128.

Mcguinness, J. (2005). A textual enactment of community: On discourse analysis, the news media and a social housing project in Tunisia in the 1990s. The Journal of North African Studies, 10: 1-18.

Mellon, J.G. (2008). Urbanism, nationalism and the politics of place: Commemoration and collective memory. Canadian Journal of Urban Research, 17: 58-77.

Mendes, M.M. (2012). Bairro da Mouraria, território de diversidade: entre a tradição e o cosmopolitismo. Sociologia, Revista da Faculdade de Letras da Universidade do Porto, Número Temático: 15-41.

Menezes, M. (2012). Debatendo mitos, representações e convicções acerca da invenção de um bairro lisboeta. Sociologia, Revista da Faculdade de Letras da Universidade do Porto, Número Temático: 69-95.

Moscovici, S. \& Markova, I. (2000). Ideas and their development, a dialogue between Serge Moscovici and Ivana Markova. In G. Duveen (ed.), Social Representations, Explorations in Social Psychology (pp. 224-286). Cambridge: Polity Press.

Pinto, P.C. (2013, May 25). A nova Mouraria. Expresso.

PDCM. (2010). Plano de Intervenção. www.aimouraria.cm-lisboa.pt/plano-de-intervencao.html [1 March 2013].

Rato, V. (2014, May 30). Intendente. A mudança em marcha. Público.

Rishbeth, C. \& Powell, M. (2012). Place attachment and memory: Landscapes of belonging as experienced post-migration. Landscape Research, 1: 1-19.

Rodrigues, W. (2010). Cidade em Transição. Nobilitação Urbana, Estilos de Vida e Reurbanização em Lisboa. Oeiras: Celta Editora.

Sani, F., Bowe, M., Herrera, M., Manna, C., Cossa, T., Miao, X. and Zhou, Y. (2007). Perceived collective continuity: Seeing groups as entities that move through time. European Journal of Social Psychology, 37: 1118-1134.

Smeekes, A., Verkuyten, M. \& Poppe, E. (2014). When national culture is disrupted: Cultural continuity and resistance to Muslim immigrants. Group Processes \& Intergroup Relations, 17: 45-66.

Wharton, C. \& Fenwick, J. (2012). Real urban images: policy and culture in northern Britain. Culture and Local Governance, 4: 1-30. 